\title{
Stimuli-responsive materials based on interpenetrating polymer liquid crystal hydrogels
}

\section{Citation for published version (APA):}

Stumpel, J. E., Gil, E. R., Spoelstra, A. B., Bastiaansen, C. W. M., Broer, D. J., \& Schenning, A. P. H. J. (2015). Stimuli-responsive materials based on interpenetrating polymer liquid crystal hydrogels. Advanced Functional Materials, 25(22), 3314-3320. https://doi.org/10.1002/adfm.201500745

\section{Document license:}

TAVERNE

DOI:

10.1002/adfm.201500745

Document status and date:

Published: 01/06/2015

\section{Document Version:}

Publisher's PDF, also known as Version of Record (includes final page, issue and volume numbers)

\section{Please check the document version of this publication:}

- A submitted manuscript is the version of the article upon submission and before peer-review. There can be important differences between the submitted version and the official published version of record. People interested in the research are advised to contact the author for the final version of the publication, or visit the $\mathrm{DOI}$ to the publisher's website.

- The final author version and the galley proof are versions of the publication after peer review.

- The final published version features the final layout of the paper including the volume, issue and page numbers.

Link to publication

\section{General rights}

Copyright and moral rights for the publications made accessible in the public portal are retained by the authors and/or other copyright owners and it is a condition of accessing publications that users recognise and abide by the legal requirements associated with these rights.

- Users may download and print one copy of any publication from the public portal for the purpose of private study or research.

- You may not further distribute the material or use it for any profit-making activity or commercial gain

- You may freely distribute the URL identifying the publication in the public portal.

If the publication is distributed under the terms of Article 25fa of the Dutch Copyright Act, indicated by the "Taverne" license above, please follow below link for the End User Agreement:

www.tue.nl/taverne

Take down policy

If you believe that this document breaches copyright please contact us at:

openaccess@tue.nl

providing details and we will investigate your claim. 


\title{
Stimuli-Responsive Materials Based on Interpenetrating Polymer Liquid Crystal Hydrogels
}

\author{
Jelle E. Stumpel, Elda Renedo Gil, Anne B. Spoelstra, Cees W. M. Bastiaansen, \\ Dirk J. Broer,* and Albertus P. H. J. Schenning*
}

Stimuli-responsive materials based on interpenetrating liquid crystal-hydrogel polymer networks are fabricated. These materials consist of a cholesteric liquid crystalline network that reflects color and an interwoven poly/acrylic acid) network that provides a humidity and $\mathrm{pH}$ response. The volume change in the cross-linked hydrogel polymer results in a dimensional alteration in the cholesteric network as well, which, in turn, leads to a color change yielding a dual-responsive photonic material. Furthermore a patterned coating having responsive and static interpenetrating polymer network areas is produced that changes both its surface topography and color.

\section{Introduction}

Stimuli-responsive polymers that have adaptive functional properties are receiving a lot of interest. ${ }^{[1-4]}$ Such materials change their properties in response to an external stimulus and can be adjusted depending on the user's needs or upon environmental changes. ${ }^{[5-7]}$ It is foreseen that these smart materials will play a key role in meeting societal and industrial challenges in the fields of energy, health, and food safety. Due to their appealing responsive properties, liquid crystalline (LC) and hydrogel polymer networks are most commonly used for the preparation of smart materials due to their attractive properties. ${ }^{[8-10]}$ In LCs, operating both in dry and wet conditions, small alterations in the molecular order are translated to dimensional changes in the entire material. ${ }^{[11-14]}$ In addition programming, the molecular orientation in three dimensions leads to complex,

Dr. J. E. Stumpel, E. R. Gil, A. B. Spoelstra, Dr. C. W. M. Bastiaansen, Prof. D. J. Broer, Prof. A. P. H. J. Schenning

Functional Organic Materials and Devices Department of Chemical Engineering and Chemistry Eindhoven University of Technology Het Kranenveld 4, 5612 AZ, Eindhoven, The Netherlands

E-mail: d.broer@tue.nl; a.p.h.j.schenning@tue.nl

Prof. C. W. M. Bastiaansen

School of Engineering and Materials Science

Queen Mary, University of London

Mile End Road, London E1 4NS, UK

Prof. D. J. Broer, Prof. A. P. H. J. Schenning

Institute for Complex Molecular Systems (ICMS)

P.O. Box 513

$5600 \mathrm{MB}$, Eindhoven, The Netherlands

DOI: 10.1002/adfm.201500745 anisotropic deformations and optical changes. ${ }^{[9,15]}$ On the other hand, large volumetric responses can be obtained in hydrogels operating in wet conditions leading to isotropic swelling. ${ }^{[16]}$ However, the introduction of new functionalities or improving existing properties in both polymer materials remains a challenge.

The use of an interpenetrating polymer network (IPN), which consists of two separate but interwoven polymer networks, is a method that is often used in polymer science to control, enhance, and/or combine functional properties. ${ }^{[17-22]}$ IPNs based on hydrogels have been reported but the combination of LCs and hydrogels has not been explored. ${ }^{[23-25]}$ In the latter case, the anisotropic and molecular order of liquid crystals can be combined with the responsive isotropic properties of hydrogels. ${ }^{[26-28]}$ Here, we report on the preparation of cholesteric liquid crystalline (CLC)-poly(acrylic acid) hydrogel-based IPNs, resulting in an anisotropic hydrogel-like material that exhibits enhanced and combined functional properties. CLCs, due to their 3D order, are able to selectively reflect incident light while poly(acrylic acid) is $\mathrm{pH}$ - and humidity responsive. ${ }^{[10,29-31]}$ The CLC-hydrogel IPN shows a response $\mathrm{e}^{[32-35]}$ in which both optical and topographical alterations can be induced.

\section{Results and Discussion}

To fabricate the sequential CLC-hydrogel IPN, the CLC polymer network was prepared first. In the CLC mixture $(\mathbf{1}, \mathbf{2}, \mathbf{3}$, 4 and 5, ratio: $4,64,30,1$, and 1 wt\% respectively, Scheme 1) a nonpolymerizable mesogen $3(5 \mathrm{CB})$ is present as a removable compound to generate easy access for other molecules to penetrate into the material. ${ }^{[3,37]}$ For the preparation of the CLC polymer network (Scheme 2), the mixture was aligned by shear force and photopolymerized onto a glass substrate, which was functionalized with methacrylate groups, resulting in an orange-reflecting polymer coating with a reflection band of $\lambda_{\max }=620 \mathrm{~nm}$ (Figure S1, Supporting Information). In order to create free volume in the polymer network, 3 needs to be removed from the coating, which was achieved by heating the sample at $140{ }^{\circ} \mathrm{C}$ for $15 \mathrm{~min}$. After this procedure, the film turned purple and the reflection band shifts to $\lambda_{\max }=420 \mathrm{~nm}$, revealing that the cholesteric order is preserved and the helical pitch had decreased (Figure S1, Supporting Information). As the helical structure is fixed after polymerization, the shrinkage 


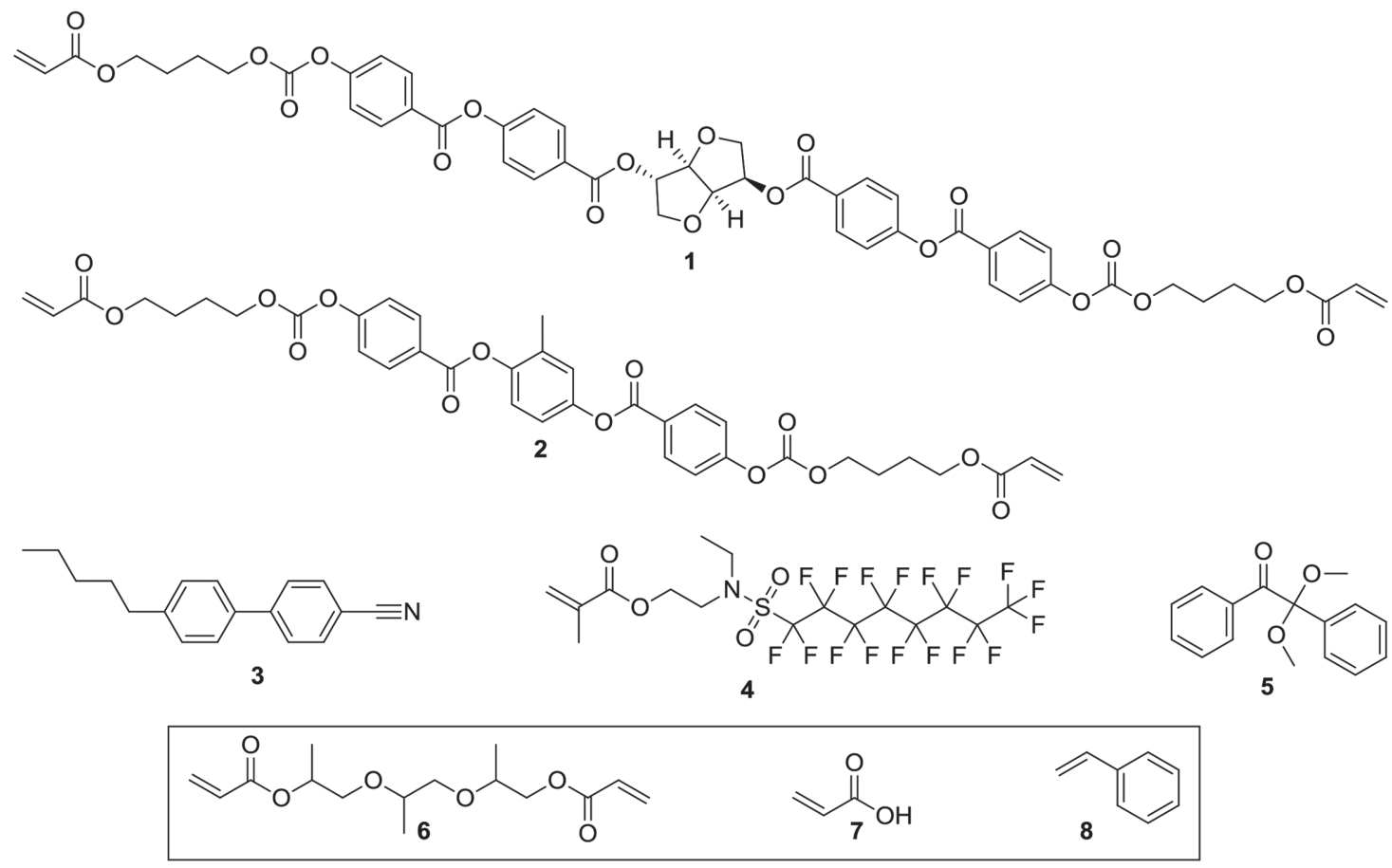

Scheme 1. Structures of the compounds used for the preparation of cholesteric coatings: chiral dopant $\mathbf{1}$, nematic monomer $\mathbf{2}$, nematic mesogen $\mathbf{3}$, surfactant $\mathbf{4}$, and photoinitiator $\mathbf{5}$. The mixture was dissolved in xylene, 1:1, prior to being used. Monomers 6, 7, and $\mathbf{8}$ were used for the preparation of the different IPNs (tripropylene glycol diacrylate, acrylic acid, and styrene, respectively).

in pitch length is related to a decrease in the thickness of the sample, which was confirmed by interferometry (Table S1, Supporting Information). Removal of $\mathbf{3}$ was additionally confirmed by Fourier transform infrared spectroscopy (FT-IR) analysis, i.e., the characteristic signal for a cyano bond disappeared, and thermogravimetric analysis, where a weight loss of $30 \%$ was observed (Figure S2, Supporting Information). This weight loss is in agreement with the decrease of the helical pitch (32\%) assuming that the evaporated liquid crystal has about the same density as the polymer network. The shrinkage takes place along z-director in this substrate confined film.

The addition of a drop of acrylic acid (7, Scheme 1$)$ on top of the polymer coating resulted in a color change from purple to green (Figure 1b) indicating swelling of the CLC network by the acrylic acid monomer without losing the anisotropy in the cholesteric network. It should be noted that coatings which were prepared without the use of the nonpolymerizable mesogen 3 could not be swollen. The polymer coating was swollen with acrylic acid containing $1 \mathrm{wt} \%$ of both cross-linker tripropylene glycol diacrylate (6) and photoinitiator 5 . After 15 min, no additional swelling was optically observed and the mixture was photopolymerized (see experimental details in Supporting Information). Transmission FT-IR spectroscopy showed signals between 1800 and $1650 \mathrm{~cm}^{-1}$ pointing to presence of a carboxylic acid, while the absence of additional acrylic signals confirmed a high degree of polymerization (Figure S3, Supporting Information). The polymer film showed a reflection band of $\lambda_{\max }$ $=520 \mathrm{~nm}$ with a bandwidth of $70 \mathrm{~nm}$ (Figure 1a) indicating an increase in the helical pitch after formation of the second network. Transmission electron microscopy (TEM) of a crosssection of the polymer coating showed periodic alternating dark and bright bands with a periodicity of $188 \mathrm{~nm}$ as a result of the periodic orientation of the molecules (Figure 1c, S5, Supporting Information). ${ }^{[38]}$ This center-to-center distance corresponds
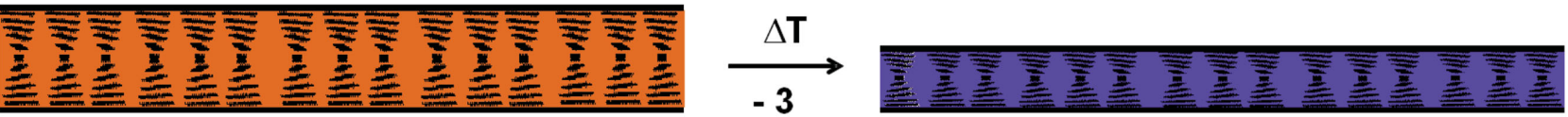

Swell with 6,7
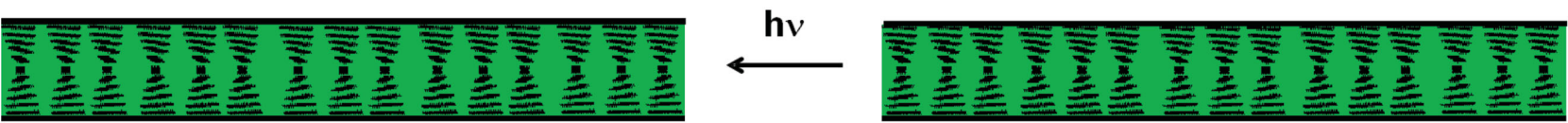

Scheme 2. Schematic representation of the sequential preparation procedure of the stimuli-responsive CLC-hydrogel IPN polymer film. 
a

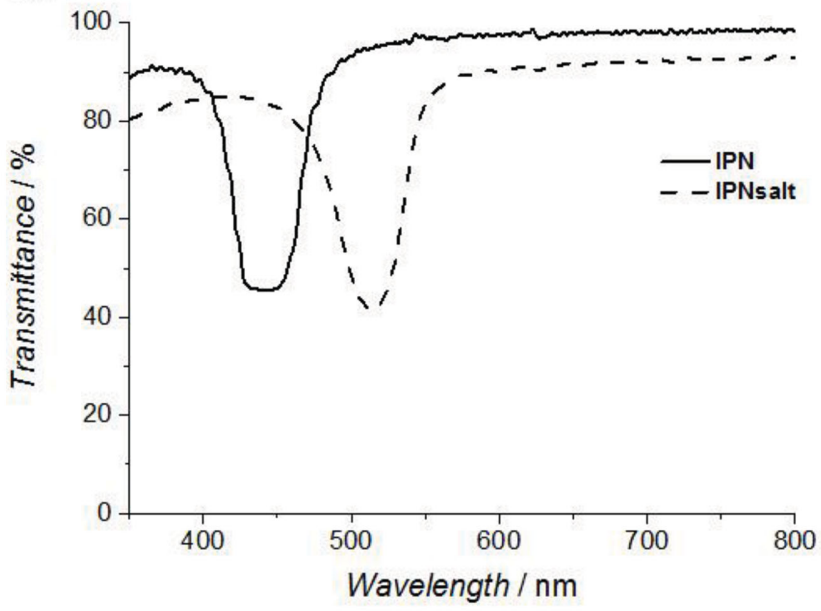

b

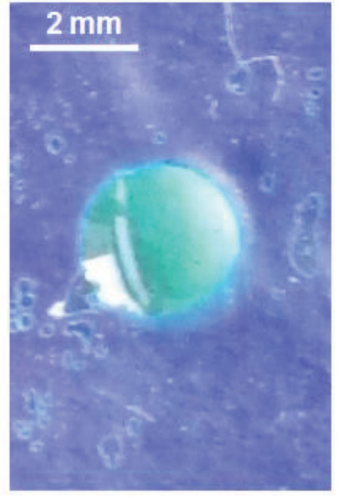

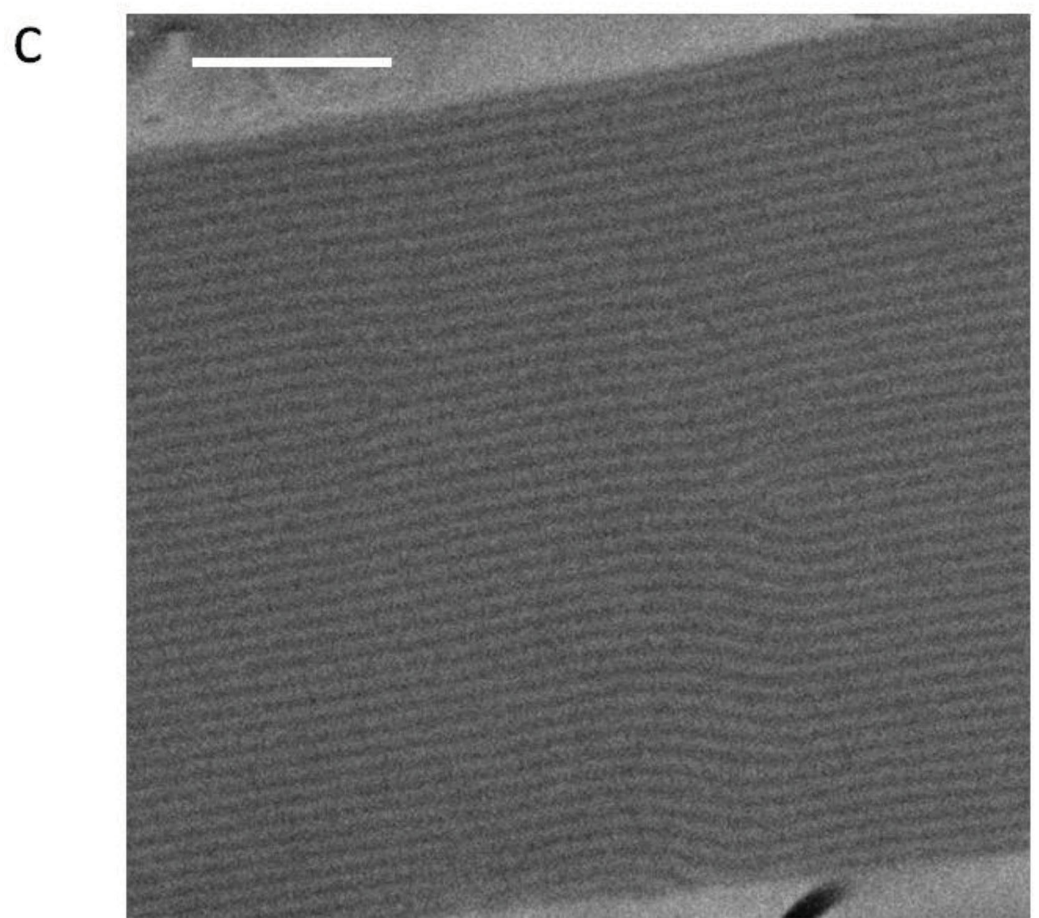

Figure 1. a) UV-Vis spectra of the IPN polymer and IPN polymer salt film, b) purple IPN polymer film with a drop of acrylic acid on top, resulting in a green color. c) TEM cross-section image of the IPN polymer salt film. The sample reveals bright and dark areas that are related to the anisotropy of the cholesteric orientation. The scale bar represents $2 \mu \mathrm{m}$.

to half the pitch of the cholesteric helix, which is in agreement with the position and typical bandwidth of the reflection band observed. The pitch size is homogeneously distributed through the sample indicating that the two polymer networks are properly mixed. Analysis of the pitch size, reflection band, and thickness of IPN coating reveals that similar increases are observed with all these techniques for each sample (Table S1, Supporting Information). The combined data reveals that an IPN of poly(acrylic acid) and a polymer CLC network has been formed.
In order to investigate the $\mathrm{pH}$ response of the IPN network, the polymer film was alternately placed in buffer solutions of $\mathrm{pH} 9$ and 3. ${ }^{[16]}$ At $\mathrm{pH}$ 9, the IPN polymer film turned red $\left(\lambda_{\max }=730 \mathrm{~nm}\right)$ while it became green again at $\mathrm{pH} 3\left(\lambda_{\max }=\right.$ $563 \mathrm{~nm}$, Figure 2). The response of the coating remains the same after several cycles. At pH 9, poly(acrylic acid) is deprotonated $^{[6]}$ leading to a polymer hydrogel salt that swells in water. Since the number of helical turns in the CLC network is fixed, swelling leads to an increase of the helical pitch and therefore a color change as the two polymer networks cannot separate 


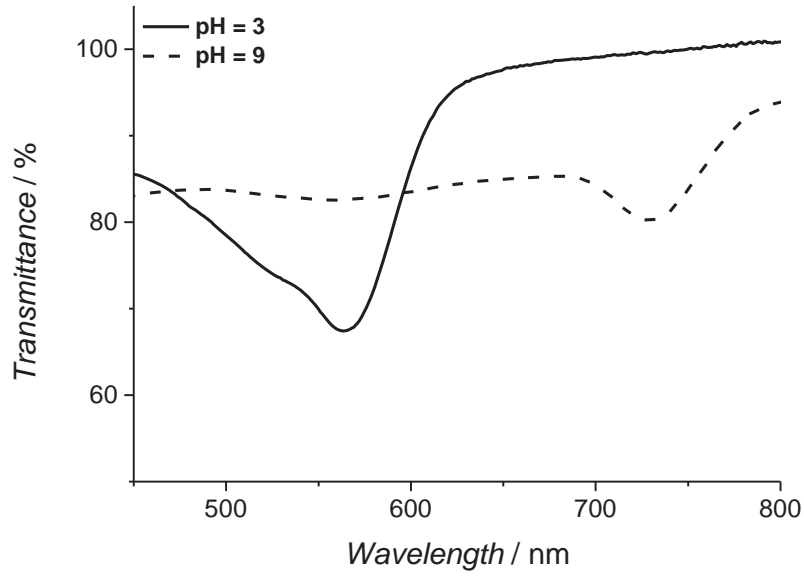

Figure 2. UV-Vis spectra of the IPN polymer salt film at $\mathrm{pH} 3$ and 9 showing a reflection band at $563 \mathrm{~nm}$ and $730 \mathrm{~nm}$, respectively.

from each other. At $\mathrm{pH}$ 3, poly(acrylic acid) is formed again leading to the green reflection color. It should be noted that the reflection band at $\mathrm{pH} 3$ is slightly red-shifted compared to the reflection band of the pristine IPN coating, which might be due a small amount of water that remains in the polymer film.

In order to fabricate a humidity-responsive optical coating, the IPN film was activated by immersing the coating in a $0.1 \mathrm{M} \mathrm{KOH}$ solution for $16 \mathrm{~h}$, resulting in the IPN polymer salt film, in which the poly(acrylic acid) network was successively converted to the corresponding potassium poly(acrylate) salt. The FT-IR spectrum shows the appearance of a signal at $1573 \mathrm{~cm}^{-1}$ indicating the formation of carboxylate ions (Figure S3, Supporting Information). TEM and transmission spectroscopy showed that the pitch size and the reflection band of the IPN slightly decreased at ambient conditions (Figures S4, S5, Supporting Information).

When the IPN polymer salt film was placed in demineralized water, its color changed from green $(530 \mathrm{~nm})$ to the near infrared (750 nm) as a result of swelling of the coating (Figure S4, Supporting Information), similar to the $\mathrm{pH}$-responsive behavior. The influence of humidity on the IPN film was studied in a gas flow chamber equipped with a UV-Vis spectrophotometer. When the relative humidity (RH) was low $(6 \%)$, the reflection band was positioned at $497 \mathrm{~nm}$, whereas a reflection band of 650 nm was observed at high humidity (85\%) (Figure 3). Between 25\% and 70\% RH, there is an almost linear relationship between the $\mathrm{RH}$ and the reflected color. The hygroscopic hydrogel network absorbs more water at high humidity, leading to enhanced swelling of the polymer film. At higher $\mathrm{RH}$, the overall

b transparency of the coating decreases, probably as a result of water condensing on top of the coating. Furthermore, the bandwidth of the reflection band increased, which is probably the result of a pitch gradient throughout the film in combination with a change in the refractive index due to the adsorption of water. Interferometry measurements shows that the thickness at a RH of $84 \%$ is 1.35 times higher than at a $\mathrm{RH}$ of $5 \%$ (Figure 3), which is comparable with the changes in the reflection band. The change in reflection band is larger than earlier reported for CLC films ${ }^{[39]}$ and in the same range as seen in photonic materials for which the highest humidity-dependent color changes has been reported. ${ }^{[40,41]}$ The response time of the coating was just several seconds and switching is possible multiple times indicating a fully reversible process. Furthermore, breathing in the proximity of the sample led immediately to a color change.

In the next step, a dual-responsive patterned polymer coating having two different IPNs was fabricated, which alters both its color and topography as a response to humidity changes. A two-step mask exposure procedure and styrene (8, Scheme 1) as additional monomer led to IPNs (see experimental details in Scheme 3) with polystyrene and responsive poly(acrylate)
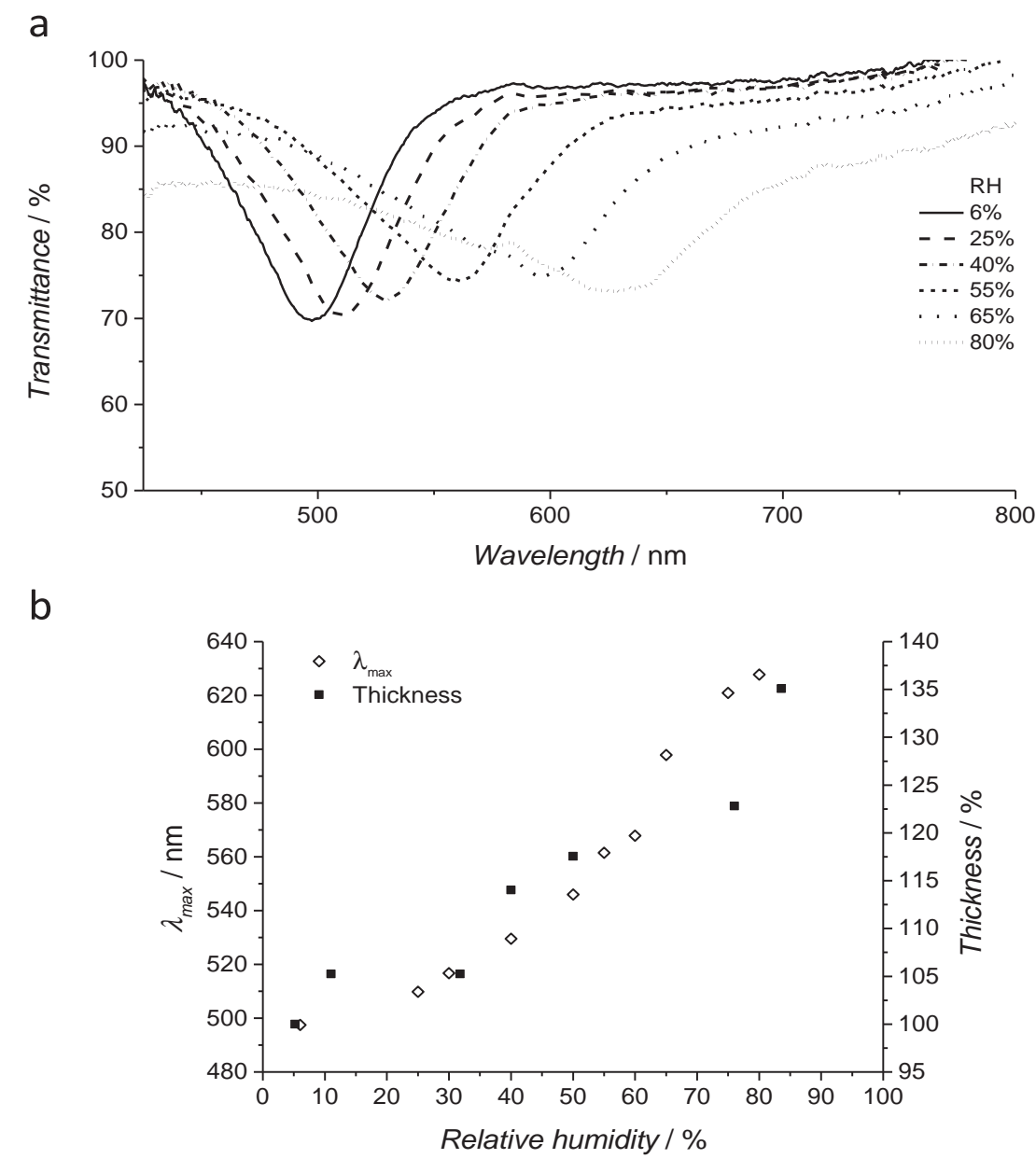

Figure 3. a) UV-Vis spectra of IPN polymer salt films as function of the $\mathrm{RH}, \mathrm{b}$ ) change of the $\lambda_{\max }$ and the thickness of the IPN polymer salt film, as function of the RH. 

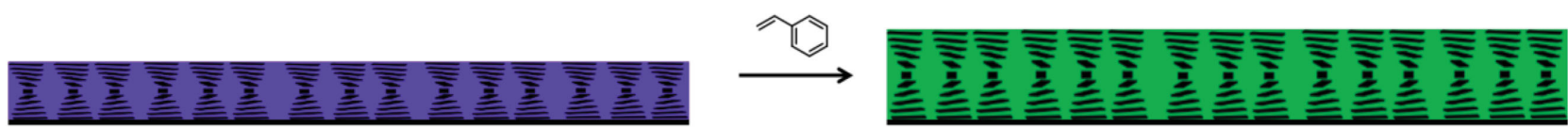

Masked photo-exposure

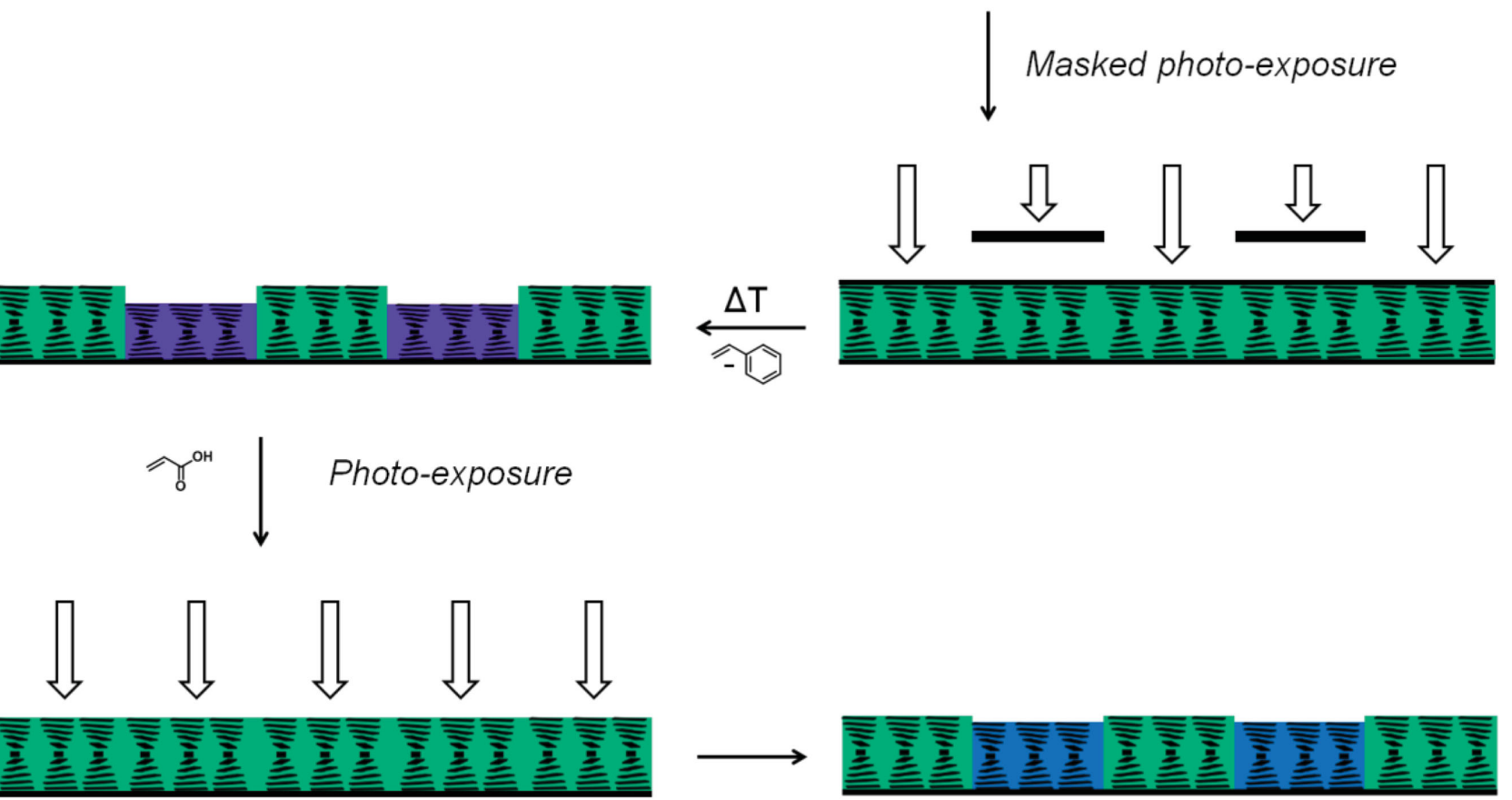

Scheme 3. Schematic representation of the sequential preparation procedure of a dual-responsive patterned coating containing two different IPNs (polystyrene and poly(acrylic acid) regions). A line mask with alternating dark and transparent areas of $1 \mathrm{~mm}$ was used in order to clearly observe the optical changes.

regions. A polymer coating was swollen with styrene containing $1 \mathrm{wt} \%$ of both cross-linker $\mathbf{6}$ and photoinitiator $\mathbf{5}$. Masked exposure results in partially polymerized styrene networks. Styrene monomer in the unexposed areas was evaporated at elevated temperature, leading line areas. Subsequently, the remaining unexposed areas were filled with the acrylic acid mixture and the coating was subsequently flood exposed with UV light resulting in a patterned coating with the two different IPN networks. Initially, the polystyrene areas were slightly thicker than the poly(acrylic acid) areas. Similar to the nonpatterned coating, the patterned coatings also show $\mathrm{pH}$-responsive color changes a result of swelling and shrinkage in the poly(acrylic acid) regions (Figure 4d).

For the humidity-responsive surface relief structure, the patterned IPN coating was treated with an alkaline solution (vide supra). In this patterned coating, the polystyrene areas remain unaffected by changes in the $\mathrm{RH}$, while the poly(acrylate) regions absorb water, increase their thickness, and change their reflection band (Figure 4a). At ambient conditions, the surface topography was homogeneously colored and almost flat (Figure 4c, Table S2, Supporting Information). The poly(acrylate) regions are humidity responsive while the polystyrene areas did not alter when the $\mathrm{RH}$ changed and so, when $\mathrm{RH}$ increased, distinct alternating green and red regions could be clearly observed with the naked eye. Both the change in relief structure and the change in the reflection band are reversible. It should be noted that the optical response in the patterned IPN is smaller than in homogeneous IPNs (a change of $50 \mathrm{~nm}$ in the reflection band, compared to $150 \mathrm{~nm})$. This could be due to rigidity of the polystyrene network, which imposes constraints on the swelling of the poly(acrylate) network.

\section{Conclusion}

A new type of stimuli-responsive IPN was prepared by combining a cross-linked hydrogel with a LC polymer network in a single coating material. A cholesteric LC polymeric template coating was swollen with a monomeric mixture of acrylic acid and a cross-linking agent, and subsequently polymerized to result in a hydrogel network. This optical material is $\mathrm{pH}$ and humidity responsive. In addition, a patterned IPN coating was prepared containing two different IPNs resulting in a dual-responsive coating changing both its topography and color. Our results show that IPNs can be produced in which the programmed 3D orientation of LC materials can be combined with the responsive properties of hydrogels. In general, this study shows that both enhanced and novel properties can be introduced in stimuli-responsive materials by using interpenetrating networks of hydrogels and liquid crystals. This opens up numerous opportunities to control, enhance, and/ or combine functional and responsive properties in smart materials. 
a

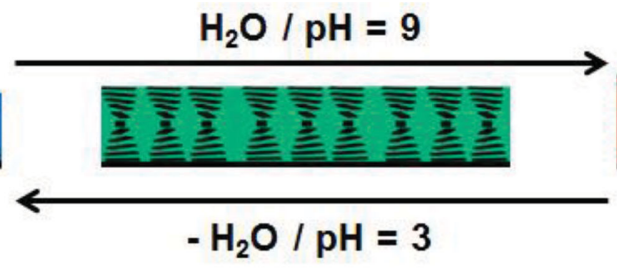

b

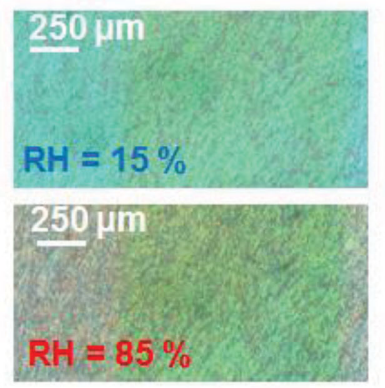

C

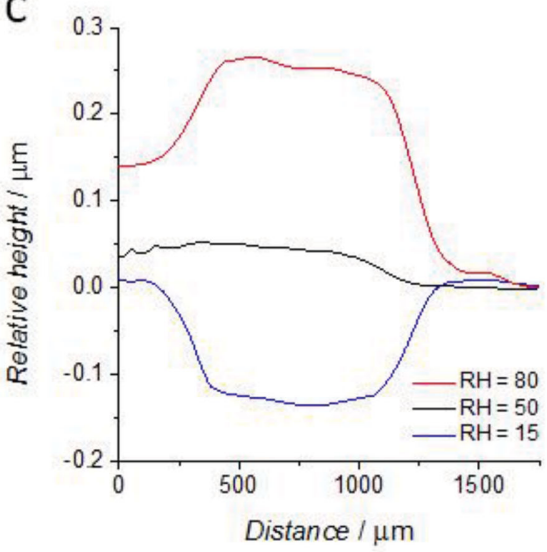

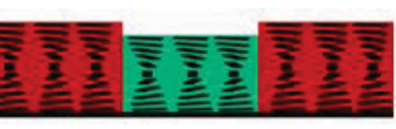

d
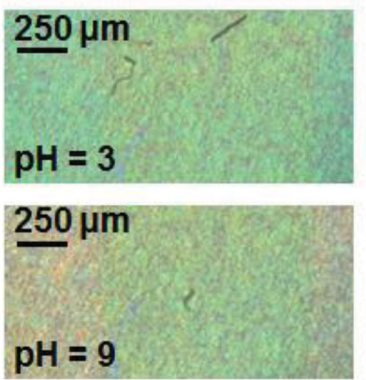

Figure 4. a) Schematic representation of the working mechanism of the patterned polystyrene poly(acrylic acid)-responsive IPN polymer film. b) Optical micrographs of a patterned IPN coating at a RH of $15 \%$ and $85 \%$. The color change in the poly (acrylate) areas is clearly visible. c) Surface topography of the patterned humidity-responsive IPN coating at $\mathrm{RH}=15 \%, 50 \%$, and $80 \%\left(T=20^{\circ} \mathrm{C}\right)$, as observed by interferometry. d) Optical micrographs of the patterned IPN polymer film at a pH 3 and 9. The scale bar represents $250 \mu \mathrm{m}$. The mask used has alternating dark and transparent areas of $1 \mathrm{~mm}$.

\section{Experimental Section}

Materials: Unless stated otherwise, all reagents and chemicals were obtained from commercial sources. Compounds 1 and $\mathbf{2}$ were purchased from BASF. Photoinitiator 5 (Irgacure 651) and surfactant 4 (2-( $N$-ethylperfluorooctanesulfonamido)ethyl methacrylate) were obtained from Ciba Specialty Chemicals and Acros Chemicals, respectively. Nematic mesogen $\mathbf{3}$ was obtained from Merck. All solvents were obtained from Biosolve. The silanes for substrate modification were obtained from Sigma-Aldrich. Buffer solutions of $\mathrm{pH} 3$ and 9 were obtained from Fluka.

Characterization of Materials: Spin coating was performed on a Karl Suss RC6 spin coater. The UV-light intensities produced by the collimated EXFO Omnicure S2000 lamp were determined using a UV Power Puck II by EIT Instrument Markets Group. A Shimadzu UV-3102 PC spectrometer was used for UV-Vis spectroscopy of the films. An HR2000+ high-resolution spectrometer from Ocean Optics mounted on a DM6000 M microscope from Leica microsystems was used for timedependent UV-Vis spectroscopy of the films. The corresponding light source emits between 400 and $800 \mathrm{~nm}$. A Varian $670 \mathrm{FT}$-IR spectrometer was used to record transmission IR spectra. The same device with a slide-on ATR crystal (Ge) and a Varian-3100 FT-IR spectrometer were used to measure reflection IR spectra. Height profiles of patterned films were recorded using a 3D interferometer (Fogale Nanotech Zoomsurf). Differential scanning calorimetry was performed on a DSC Q1000 from TA instruments and a TGA Q500 from TA instruments was used for thermogravimetric analysis. Scanning electron microscopy was done on a SEM-Quanta 3D, FEl, cross-sections were prepared by fracturing the films in liquid nitrogen. The thin films were embedded in an epoxy resin (Epofix) at $70^{\circ} \mathrm{C}$. Ultrathin sections were obtained at room temperature using a Leica Reichert Ultracut $S$ microtome equipped with a Diatome $45^{\circ}$ knife (cutting direction perpendicular to the CLC director). The sections were transferred to a 200 mesh copper grid with a carbon support layer. Transmission electron microscopy was performed using a Tecnai 20 microscope, operated at $200 \mathrm{kV}$.
Monomer Mixtures: The monomer mixture for the preparation of the IPN contains 4, 64, 30, 1, 1 wt\% of 1, 2, 3, 4, and 5, respectively) in xylene $(1: 1)$. The mixture for the coating without 3 is similar, but contains 94 wt\% of 2.

Glass Functionalization: Glass substrates were cleaned by sonication (ethanol, $15 \mathrm{~min}$ ) followed by treatment in a UV-ozone photoreactor (Ultra Violet Products, PR-100, 20 min). The surface of the glass substrates was modified by spin coating 3-(trimethoxysilyl)propyl methacrylate solution (1 vol\% solution in a 1:1 water-isopropanol mixture) or $1 \mathrm{H}, 1 \mathrm{H}, 2 \mathrm{H}, 2 \mathrm{H}$ perfluorodecyltriethoxysilane solution (1 vol\% solution in ethanol) onto the activated glass substrate for $45 \mathrm{~s}$ at $3000 \mathrm{rpm}$. After curing for $10 \mathrm{~min}$ at $100^{\circ} \mathrm{C}$, the substrates were ready to use.

Preparation of the CLC Coatings: Cholesteric coatings with a typical thickness of between 8 and $10 \mu \mathrm{m}$ were prepared as follows: $10 \mu \mathrm{L}$ of the CLC mixture (dissolved 1:1 in xylene) was placed on a methacrylatefunctionalized substrate at $95{ }^{\circ} \mathrm{C}$ and the solvent was allowed to evaporate. After the complete evaporation of xylene, a perfluorodecyltriethoxysilane-functionalized glass substrate was placed on top and pressed firmly. At lower temperatures, the chiral nematic liquid crystal mixture was aligned by shear forces. The contents of the cells were photopolymerized at room temperature for $300 \mathrm{~s}\left(48 \mathrm{~mW} \mathrm{~cm}{ }^{-2}\right.$ intensity in the range $320-390 \mathrm{~nm}$ ).

Removal of the Non-Reactive Mesogen 3: In order to remove 3 from the polymer film, the sample was heated at $140{ }^{\circ} \mathrm{C}$ for $10 \mathrm{~min}$. During this process, the initially yellow-orange reflecting film turned blue. Various techniques confirmed that $\mathbf{3}$ was fully removed from the coating.

Preparation of the CLC-Hydrogel IPN: A drop of acrylic acid (7) with 1 wt $\%$ cross-linker 6 and 1 wt\% of photoinitiator 4 was placed on the polymer coating. In order to prevent evaporation, a glass sheet was placed on top. The monomer mixture was allowed to swell for $15 \mathrm{~min}$, after which no additional visible color change was observed. The upper glass plate was removed and excess of monomer mixture was removed before a perfluorodecyl-triethoxysilane-functionalized glass slide was placed on top and the mixture was photopolymerized for $300 \mathrm{~s}$ (48 $\mathrm{mW} \mathrm{cm} \mathrm{cm}^{-2}$ intensity in the range $320-390 \mathrm{~nm}$ ). 
Preparation of IPN Polymer Salts: The films containing poly(acrylic acid) were placed in a $0.1 \mathrm{M} \mathrm{KOH}$ solution for $16 \mathrm{~h}$ to ensure full formation of the corresponding carboxylate salt.

\section{Supporting Information}

Supporting Information is available from the Wiley Online Library or from the author.

\section{Acknowledgements}

The research was made possible by a $\mathrm{VICl}$ grant of The Netherlands Foundation for Scientific Research (NWO).

Received: February 24, 2015 Revised: March 26, 2015 Published online: April 17, 2015

[1] C. Alexander, K. M. Shakesheff, Adv. Mater. 2006, 18, 3321.

[2] H. Meng, J. Hu, J. Intell. Mater. Syst. Struct. 2010, 21, 859.

[3] Q. Li, Intelligent Stimuli-Responsive Materials, John Wiley \& Sons, Inc., Hoboken, NJ 2013.

[4] H. Meng, G. Li, J. Mater. Chem. A 2013, 1, 7838.

[5] A. Pucci, R. Bizzarri, G. Ruggeri, Soft Matter 2011, 7, 3689.

[6] I. B. Burgess, M. Loncar, J. Aizenberg, J. Mater. Chem. C 2013, 1, 6075.

[7] J. Ge, Y. Yin, Angew. Chem., Int. Ed. 2011, 50, 1492.

[8] J. M. Spruell, C. J. Hawker, Chem. Sci. 2011, 2, 18.

[9] J. E. Stumpel, D. J. Broer, A. P. H. J. Schenning, Chem. Commun. 2014, 50, 15839.

[10] Q. Li, Liquid Crystals Beyond Displays, John Wiley \& Sons, Inc., Hoboken, NJ 2012.

[11] D. Liu, D. J. Broer, Liq. Cryst. Rev. 2013, 1, 20.

[12] D. Liu, D. J. Broer, Langmuir 2014, 30, 13499.

[13] T. Seki, Macromol. Rapid Commun. 2014, 35, 271.

[14] M. A. Haque, T. Kurokawa, J. P. Gong, Soft Matter 2012, 8, 8008.

[15] L. T. de Haan, A. P. H. J. Schenning, D. J. Broer, Polymer 2014, 55, 5885.

[16] D. Liu, C. W. M. Bastiaansen, J. M. J. den Toonder, D. J. Broer, Soft Matter 2013, 9, 588
[17] L. H. Sperling, J. Polym. Sci., Part D: Macromol. Rev. 1977, 12, 141.

[18] L. H. Sperling, in Encyclopedia of Polymer Science and Technology, John Wiley \& Sons, Inc., HobokenNJ 2002.

[19] L. H. Sperling, V. Mishra, Polym. Adv. Technol. 1996, 7, 197.

[20] D. Myung, D. Waters, M. Wiseman, P.-E. Duhamel, J. Noolandi, C. N. Ta, C. W. Frank, Polym. Adv. Technol. 2008, 19, 647.

[21] Y. S. Lipatov, T. T. Alekseeva, in Phase-Separated Interpenetrating Polymer Networks, Vol. 208, Springer-Verlag Berlin, Berlin 2007, 1.

[22] Y. F. Yue, M. A. Haque, T. Kurokawa, T. Nakajima, J. P. Gong, Adv. Mater. 2013, 25, 3106

[23] E. S. Dragan, Chem. Eng. J. 2014, 243, 572.

[24] T. Ube, K. Takado, T. Ikeda, Mol. Cryst. Liq. Cryst. 2014, 594, 86.

[25] Y. Zhao, G. Yuan, Macromolecules 1996, 29, 1067.

[26] G. A. Becht, M. Sofos, S. Seifert, M. A. Firestone, Macromolecules 2011, 44, 1421.

[27] K. Boudraa, T. Bouchaour, U. Maschke, Macromol. Symp. 2011, 303, 95.

[28] Y. Zhao, G. Yuan, P. Roche, Polymer 1999, 40, 3025.

[29] D.-J. Mulder, A. P. H. J. Schenning, C. W. M. Bastiaansen, J. Mater. Chem. C 2014, 2, 6695.

[30] H. K. Bisoyi, Q. Li, Acc. Chem. Res. 2014, 47, 3184.

[31] T. J. White, M. E. McConney, T. J. Bunning, J. Mater. Chem. 2010, 20, 9832.

[32] M. K. Khan, W. Y. Hamad, M. J. MacLachlan, Adv. Mater. 2014, 26, 2323.

[33] L. T. de Haan, V. Gimenez-Pinto, A. Konya, T.-S. Nguyen, J. M. N. Verjans, C. Sánchez-Somolinos, J. V. Selinger, R. L. B. Selinger, D. J. Broer, A. P. H. J. Schenning, Adv. Funct. Mater. 2014, 24, 1251

[34] L. Bai, Z. Xie, W. Wang, C. Yuan, Y. Zhao, Z. Mu, Q. Zhong, Z. Gu, ACS Nano 2014, 8, 11094.

[35] M. M. Hawkeye, M. J. Brett, Adv. Funct. Mater. 2011, 21, 3652.

[36] C.-K. Chang, C. M. W. Bastiaansen, D. J. Broer, H.-L. Kuo, Adv. Funct. Mater. 2012, 22, 2855.

[37] C.-K. Chang, C. W. M. Bastiaansen, D. J. Broer, H.-L. Kuo, Macromolecules 2012, 45, 4550.

[38] T. J. Bunning, D. L. Vezie, P. F. Lloyd, P. D. Haaland, E. L. Thomas, W. W. Adams, Liq. Cryst. 1994, 16, 769.

[39] N. Herzer, H. Guneysu, D. J. D. Davies, D. Yildirim, A. R. Vaccaro, D. J. Broer, C. W. M. Bastiaansen, A. P. H. J. Schenning, J. Am. Chem. Soc. 2012, 134, 7608.

[40] E. Kim, S. Y. Kim, G. Jo, S. Kim, M. J. Park, ACS Appl. Mater. Interfaces 2012, 4, 5179.

[41] E. Tian, J. Wang, Y. Zheng, Y. Song, L. Jiang, D. Zhu, J. Mater. Chem. 2008, 18, 1116. 